\title{
Visual Motion-Detection Circuits in Flies: Parallel Direction- and Non-Direction-Sensitive Pathways between the Medulla and Lobula Plate
}

\author{
John K. Douglass and Nicholas J. Strausfeld \\ Arizona Research Laboratories, Division of Neurobiology, University of Arizona, Tucson, Arizona
}

The neural circuitry of motion processing in insects, as in primates, involves the segregation of different types of visual information into parallel retinotopic pathways that subsequently are reunited at higher levels. In insects, achromatic, motionsensitive pathways to the lobula plate are separated from colorprocessing pathways to the lobula. Further parallel subdivisions of the retinotopic pathways to the lobula plate have been suggested from anatomical observations. Here, we provide direct physiological evidence that the two most prominent of these latter pathways are, indeed, functionally distinct: recordings from the retinotopic pathway defined by small-field bushy T-cells (T4) demonstrate only weak directional selectivity to motion, in striking contrast with previously demonstrated strong directional selectivity in the second, T5-cell, pathway. Additional intracellular recordings and anatomical descriptions have been obtained from other identified neurons that may be crucial in early motion detection and processing: a deep medulla amacrine cell that seems well suited to provide the lateral interactions among retinotopic elements required for motion detection; a unique class of $\mathrm{Y}$-cells that provide small-field, directionally selective feedback from the lobula plate to the medulla; and a new heterolateral lobula plate tangential cell that collates directional, motion-sensitive inputs. These results add important new elements to the set of identified neurons that process motion information. The results suggest specific hypotheses regarding the neuronal substrates for motionprocessing circuitry and corroborate behavioral studies in bees that predict distinct pathways for directional and nondirectional motion.

Key words: insects; vision; parallel pathways; motion processing; bushy T-cells; motion computation
In flying insects, many behaviors rely upon visual motion information: gaze control (Hengstenberg, 1993), flight stabilization (Egelhaaf et al., 1988), deceleration (Wagner, 1982), visual tracking (Collett and Land, 1978; Egelhaaf et al., 1988; Land, 1992; Lehrer and Srinivasan, 1992), and range estimation for avoidance (Kirchner and Srinivasan, 1989; Srinivasan et al., 1991), approach, or landing (Braitenburg and Taddei Ferretti, 1966; Wagner, 1982, 1986; Sobel, 1990). Whereas some behaviors may require complex interactions among various visual processing mechanisms, others may rely on simple parameters. Landing responses and visual tracking seem to combine figure-ground discrimination with information on both the direction and speed of object motion (Collett and Land, 1978; Land, 1992). Optomotor reflexes for stable flight are sensitive to motion direction but relatively insensitive to stimulus speed and spatial structure (Borst and Egelhaaf, 1989). Evidence is accumulating that early visual processing in primates and insects segregates information among several parallel, quasi-independent pathways. Understanding the neural bases for behaviors that involve motion detection thus requires

Received March 13, 1996; revised May 8, 1996; accepted May 9, 1996.

This work was funded by a grant from the National Center for Research Resources (RR08688)

We thank Carol Arakaki, Robert Gomez, and Charles Hedgecock for excellent technical assistance and several colleagues, including Elke Buschbeck and Drs. Yongsheng Li and Martina Wicklein, for stimulating discussions and suggestions on this manuscript.

Correspondence should be addressed to John K. Douglass, Arizona Research Laboratories Division of Neurobiology, 611 Gould-Simpson Building, University of Arizona, Tucson, AZ 85721.

Copyright (C) 1996 Society for Neuroscience $0270-6474 / 96 / 164551-12 \$ 05.00 / 0$ identifying neurons involved in detecting motion as well as identifying which parameters are processed independently.

Parallel pathways that process distinct features of sensory inputs are well known in visual systems. In insects (Strausfeld and Lee, 1991; Srinivasan et al., 1993; Lehrer, 1994) and primates (Maunsel and Newsome, 1987; Livingstone and Hubel, 1988; Van Essen and Gallant, 1994), there is at least partial segregation of color and motion. In dipteran insects, the anatomical separation of color-sensitive pathways from achromatic, motion-sensitive pathways begins in the lamina and continues into the central nervous system (Strausfeld and Lee, 1991). Insect optomotor responses (Kaiser and Liske, 1974; Kaiser, 1975; Srinivasan and Guy, 1990), "movement-avoidance responses" (Srinivasan and Lehrer, 1984), and single cells in the optomotor pathway (Menzel, 1973) are color-insensitive. Behavioral experiments with bees suggest that motion processing itself is further segregated into distinct mechanisms and pathways (Srinivasan et al., 1993).

Anatomical observations (Strausfeld, 1976; Strausfeld and Lee, 1991; Buschbeck and Strausfeld, 1996) also suggest parallel subdivisions within motion-sensitive pathways (Fig. 1): each retinotopic column includes two small-field retinotopic pathways that begin with achromatic inputs from photoreceptors R1-R6. These terminate in the lamina on dendrites of the large monopolar cells (LMCs) L1 and L2 (Boschek, 1971). One pathway (T5) is defined by its long-axoned transmedullary type Tm1 neurons and their likely postsynaptic targets, type T5 bushy T-cells, the dendrites of which reside in a superficial stratum of the lobula. Tm1 receives its afferent supply via L2 and smaller lamina efferents (Strausfeld and Nässel, 1980; Buschbeck and Strausfeld, 1996). The other (T4) pathway involves short-axoned transmedullary iTm cells, the ter- 


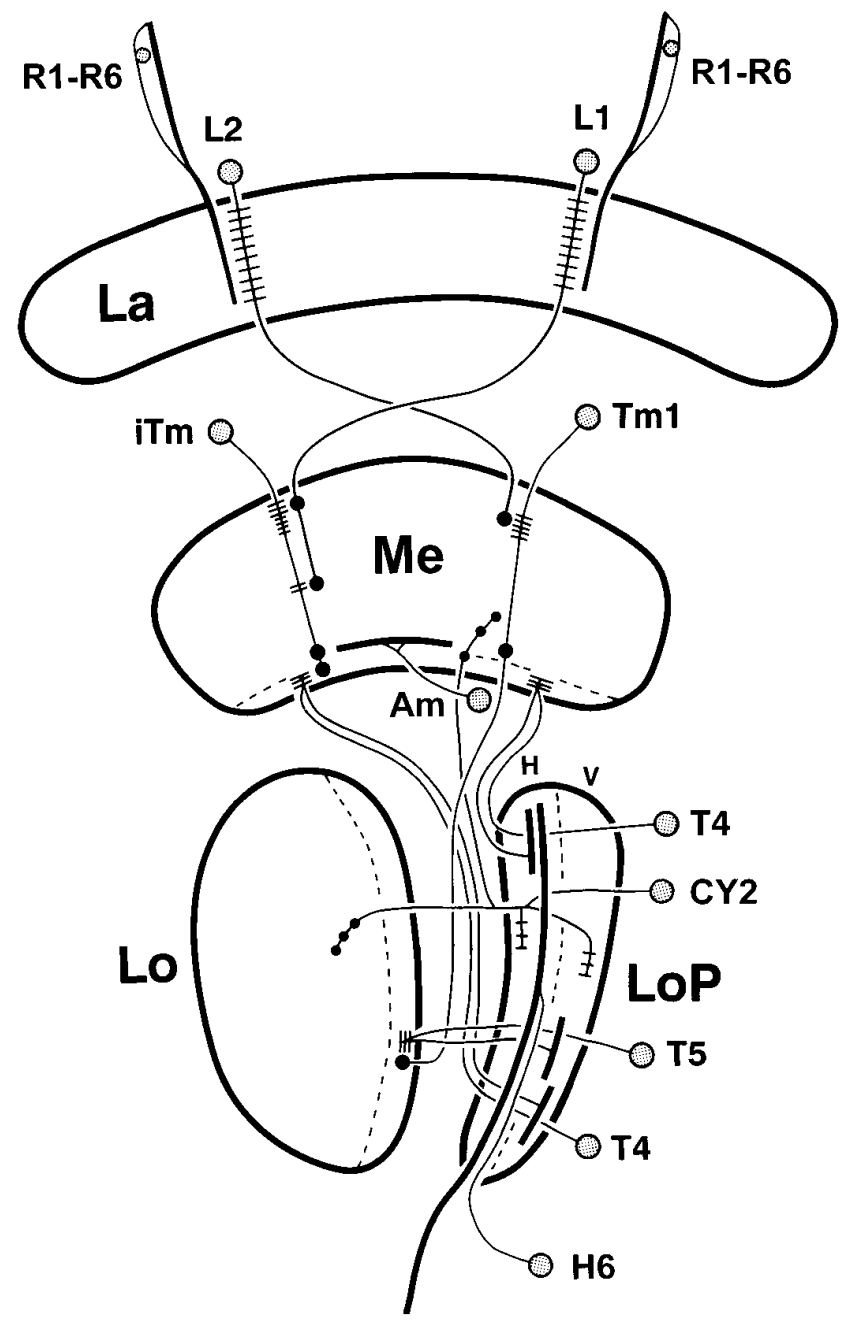

Figure 1. Schematic view of parallel pathways to the lobula plate in the calliphorid fly brain (after Douglass and Strausfeld, 1995; see also Buschbeck and Strausfeld, 1996), showing anatomical relationships among selected small-field retinotopic neurons, a medulla amacrine cell, and a wide-field lobula-plate efferent neuron (stippled circles, cell bodies). An ipsilateral optic lobe ( $L a$, lamina; $M e$, medulla; $L o$, lobula; $L o P$, lobula plate) is shown in horizontal section, with anterior to the left. Dendrites (thin bars) of large monopolar cells L1 and L2 receive achromatic inputs from photoreceptors R1-R6 and terminate ( filled circles) at characteristic levels that coincide with dendrites of the transmedullary cells $\mathrm{iTm}$ and $\mathrm{Tm} 1$. iTm terminates at $\mathrm{T} 4$ dendrites in the deep medulla. Tm 1 terminates at the T5 dendritic layer in the outer lobula. iTm and Tm1 both have output zones ( filled circles) just distal to the T4 dendritic layer in a stratum containing the deep medulla amacrine $(\mathrm{Am})$. T4 and T5 terminate (thick bars) in lobula plate strata corresponding to horizontal $(H)$ and vertical $(V)$ motion sensitivity, in which they synapse with wide-field tangential cells, exemplified by the tangential cell H6. See Results and Discussion for additional details.

minals of which, in the deepest medullary stratum, coincide with dendrites of type T4 bushy T-cells. The overlap between LMC medulla terminals and iTm dendrites (Strausfeld and Lee, 1991; Buschbeck and Strausfeld, 1996) suggests that this pathway is supplied by L1 monopolars.

A major question in vision concerns the cellular nature of elementary motion detectors (EMDs). Theoretical arguments (Hassenstein and Reichardt, 1956) and experiments involving successive stimulation of adjacent ommatidia (Buchner, 1976) suggest that the minimal functional EMD involves divergence between two adjacent photoreceptors. Riehle and Franceschini (1982) showed that an EMD must involve interactions between adjacent retinotopic columns. Directionally selective (DS) responses to motion by large lobula plate tangential neurons (Eckert and Bishop, 1978; Hausen, 1981; Hengstenberg et al., 1982) confirm the retinotopic nature of the minimal EMD (Franceschini et al., 1989) and suggest that motion detection arises distal to these neurons. Activity labeling with ${ }^{3} \mathrm{H}$-2-deoxyglucose during motion or flicker implicates loci distal to the lobula plate: the T5 and T4 dendritic layers (Fig. 1) and 2-3 outer medullary layers (Bausenwein and Fischbach, 1992). Only in lobula plate strata, however, has direction-specific staining been resolved (Buchner et al., 1984).

Until recently (Douglass and Strausfeld, 1995), intracellular recordings from identified medulla neurons were extremely rare (Devoe and Ockleford, 1976), with one tentative report of a weakly DS neuron (Gilbert et al., 1991). Our recordings from small retinotopic neurons in the fly Phaenicia have now demonstrated clear directional responses from Tm1 and T5, suggesting that the EMD circuitry is presynaptic to T5 and may involve Tm1. Although iTm exhibited distinct responses to motion and flicker, it did not have DS responses (Douglass and Strausfeld, 1995). These results clearly associate the Tm1-T5 pathway with directional motion processing and suggest a different role for the iTm-T4 pathway. Here, we focus on the potential roles of these two pathways in providing motion-specific information to the lobula plate and examine the possible roles of deep medulla amacrines and centrifugal Y-cells in motion computations.

\section{MATERIALS AND METHODS}

All experiments employed calliphorid flies, Phaenicia sericata, which are maintained as a laboratory colony at the Arizona Research Laboratories Division of Neurobiology. Eggs from locally trapped individuals were collected several times per year to help maintain the genetic diversity and fitness of the laboratory colony. As in a previous study (Douglass and Strausfeld, 1995), intracellular recordings were obtained during visual stimulation with flicker and motion, and recorded cells were stained and reconstructed with confocal and conventional epifluorescence microscopy. Here, we summarize these methods and include any differences from the previous procedures.

Electrophysiological recordings. Intact male or female flies were immobilized with low-melting-point wax, with the head tilted downward at $45^{\circ}$ from the horizontal axis. A small piece of cuticle was removed from behind the left or right brain to expose the medulla and lobula complex, and the brain was bathed in insect saline; all recordings were from the right brain, except for a medulla amacrine cell (see below). Borosilicate pipettes were filled with $4 \%$ Lucifer yellow in distilled water, backfilled with $0.1 \mathrm{M} \mathrm{LiCl}$, and inserted into the rear surface of the optic lobe with a Leitz micromanipulator. Intracellular membrane voltages were monitored with standard $\mathrm{AgCl}$ electrodes and an intracellular amplifier (Neuroprobe 1600, AM Systems, Everett, WA) and recorded on a VCR with a Vetter 3000A PCM adapter (Rebersburg, PA). Intracellular voltages were recorded on the "fast" channel $(25 \mu$ sec rise time $)$, and photodiode records of stimulus parameters were monitored on additional channels (see below). Portions of the data were later replayed from tape or were digitized on-line and stored at $10 \mathrm{kHz}$ on a PC (Datawave, Longmont, $\mathrm{CO})$ for subsequent analysis. In situ pipette resistances ranged from $\sim 70$ to $140 \mathrm{M} \Omega$. Small neurons occasionally were dye-filled unintentionally during brief penetrations. Measures taken to minimize the occurrence of multiple fills (Douglass and Strausfeld, 1995) included keeping detailed voice records during experiments, using only one pipette per preparation, and terminating the experiment at the conclusion of the first stable recording. In preparations where more than one neuron was filled, the physiological data were analyzed only if they could be unequivocally identified with a single cell (the last and most intensely filled; see Results).

Stimuli. Flies were positioned with the head at the center of the visual stimulus field, which was oriented parallel to the frontal plane of the head. All experiments were performed in a darkened room in a Faraday 
cage resting on a vibration isolation table (TMC, Peabody, MA). Impaled cells typically were stimulated first with square-wave grating motion and then with square-wave flicker, followed by additional motion or flicker stimuli when possible.

One recording from a deep amacrine cell (see Results) was obtained by using a stimulus arrangement fully described elsewhere (Douglass and Strausfeld, 1995). For this recording, square-wave grating motion and flicker stimuli were projected onto a circular rear-projection screen that presented a $108^{\circ}$ field of view. Images of high-contrast gratings with a spatial wavelength of 0.04 cycles per degree (cpd) moved in each of eight directions at a temporal frequency of $\sim 4 \mathrm{~Hz}$, and a diffuse wide-field flicker stimulus was provided by an array of green LEDs positioned behind the projection screen. Green light was used for both grating and flicker stimuli, which were adjusted to similar mean intensities (4 lux), contrast ratios $(>15)$, and spectral compositions.

All other experiments employed computer-generated visual stimuli (Vision Research Graphics, Durham, $\mathrm{NH}$ ) displayed on a high-resolution red-green-blue (rgb) monitor (Nanao 9080i, Japan). The $1024 \times 512$ pixel display was operated in rgb mode at a refresh rate of $117.3 \mathrm{~Hz}$. This system permitted the presentation of a variety of stimuli in rapid succession, a major advantage for relatively short-lived intracellular recordings from very small neurons such as $\mathrm{T} 4$ and $\mathrm{T} 5$. Up to 15 precomputed stimulus objects at a time could be selected via keyboard input. At the start of each stimulus presentation, a 4 bit stimulus identification code was sent to a parallel port for recording on the VCR tape and the data acquisition PC. Precise stimulus-timing information was provided by two photodiodes (PIN 10DP, United Detector Technology, Hawthorne, CA), one of which monitored the full stimulus field, while the other monitored an image of the center of the field provided by a small mirror, lens, and circular aperture.

The $117 \mathrm{~Hz}$ refresh rate of the stimulus monitor is nearly twice that of a standard PC display. Although calliphorid fly photoreceptors and lamina monopolar cells are capable of responding to flicker rates well above $120 \mathrm{~Hz}$, light-adapted response peaks lie below $30 \mathrm{~Hz}$ (French and Järvilehto, 1978; Laughlin, 1981), and responsiveness to higher frequencies should be minimal at the relatively low illumination intensities employed in this study (see below). To date, recordings obtained with this CRT have revealed no significant artifacts as long as the electrodes are well shielded from electromagnetic interference. The CRT was located outside of the Faraday cage, and further shielding of the preparation was provided by a grounded copper sheet placed vertically immediately in front of the fly and painted flat black to attenuate stray light. A window cut in the Faraday cage and an aperture in the copper shielding provided the fly with an unobstructed view of the stimulus screen.

As the head of the fly was tilted downward during recordings, the stimulus CRT was also tilted downward and viewed via a first-surface mirror positioned directly below the head of the fly. The path length from the center of the CRT to the compound eyes was $31 \mathrm{~cm}$, which provided a $50^{\circ}$ horizontal by $40^{\circ}$ vertical full-field view. Three basic types of square-wave stimuli were employed: a small-field, $4 \mathrm{~Hz}$ circular flicker stimulus $\left(3.5\right.$ or $7^{\circ}$ diameter $)$, a circular window showing smallfield grating motion in each of eight directions $\left(3.5^{\circ}\right.$ diameter $)$, and full-field grating motion in eight directions. The onscreen positions of small-field stimuli were controlled with a trackball. Both the small-field and wide-field gratings had a spatial frequency of $0.13 \mathrm{cpd}$. Whereas the small-field motion had a constant speed of $12 \%$ sec (temporal frequency $4 \mathrm{~Hz}$ ), wide-field motion speed was varied sinusoidally between 0 and $93^{\circ} / \mathrm{sec}(0-12 \mathrm{~Hz})$. All stimuli were generated using fixed, equal intensity values for the three color guns (100 on a $0-255$ scale); flicker "Off" and the grating trough intensities were set to 0 , resulting in measured contrast ratios of $>30$. The mean intensity of full-field gratings at the position of the head of the fly was 2.5 lux, and the display background, used for small-field stimuli and during periods between stimulus presentations, was a uniform gray field $\sim 0.6 \log$ units below the maximum stimulus intensity.

Histology and anatomical reconstructions. Cells were stained with Lucifer yellow by applying a steady 1-2 nA hyperpolarizing current for up to $3 \mathrm{~min}$. Brains were dissected away from the head capsules while immersed in fixative (4\% Mallinkrodt formalin in Millonig's buffer, $\mathrm{pH} 7.2$ ), and the retina and ommatidia were removed immediately to prevent the diffusion of fluorescent ommochrome pigments into the neural tissue. Brains were fixed for 1-2 hr at room temperature; some preparations were then fixed overnight at $4^{\circ} \mathrm{C}$. Fixed tissue was rinsed twice in Millonig's buffer, dehydrated in an ethanol series followed by acetone, embedded in Spurr's (1969), and sectioned at $14 \mu \mathrm{m}$ on a sliding microtome. Profiles of stained cells (optical sections) were scanned at $0.5-2 \mu \mathrm{m}$ intervals with a confocal epifluorescence microscope (MRC 600, Bio-Rad, Richmond, CA). Confocal projections from separate plastic sections were merged with imageprocessing software (Corel Photopaint 4, Corel, Salinas, CA), assisted by observations of stereopairs of individual projections. Some preparations were also photographed on Kodak Ektachrome 400 or Fujichrome 1600 at $1 \mu \mathrm{m}$ intervals with a Leitz Diaplan epifluorescence microscope. Reconstructions were drawn from projected photographs of conventional epifluorescence images or confocal images.

\section{RESULTS}

Intracellular recordings and Lucifer yellow injections were employed to investigate the morphologies and roles of small-field columnar inputs to the lobula plate (T4), wide-field projection and amacrine cells (H6, deep medulla amacrine), and centrifugal Y-cells (CY1 and CY2) in processing visual motion information. The recordings presented here illustrate some of the variety of nonspiking and spiking behaviors that are typical of many neurons involved in early visual processing in insects. None of the cells described in this report has, to our knowledge, been recorded from previously.

\section{A deep medulla amacrine with nondirectional responses}

Figure 2 illustrates a wide-field amacrine cell that is intrinsic to the proximal medulla. This neuron may be homologous to a similar neuron named m:tan5 in the Syrphid fly, Eristalis tenax, which was believed to be an output tangential cell, but the location of the cell body was not determined (Strausfeld, 1970). The cell body of the amacrine illustrated in Figure 2 lies behind the proximal medulla, and its arborizations define an oval-shaped receptive field restricted to the medulla layer designated $\mathrm{m} 9$ in Drosophila melanogaster (Fischbach and Dittrich, 1989), which lies immediately distal to the T4 stratum, m10. Layer m9 includes projections from small-field retinotopic cells in the optomotor pathway such as iTm and Tm1, arborizations of various Y-cells destined for the lobula and lobula plate, and a possible input region of the lamina centrifugal cell C3 (Strausfeld and Nässel, 1980). The anatomical receptive field of the deep medulla amacrine spanned $\sim 20$ retinotopic columns vertically and $\sim 5-7$ columns horizontally. In contrast, the major axis of m:tan5 projections was horizontal (Strausfeld, 1970).

In response to wide-field flicker (Fig. $2 A$ ), the deep medulla amacrine showed a transient $2-3 \mathrm{mV}$ depolarization to Off and little or no On response. Responses to motion consisted of transient depolarizations at the temporal frequency of the grating. The receptive field characteristics of this neuron were not examined in detail. Stimulation with vertical motion in a $37^{\circ}$ field, however (obtained with a circular aperture positioned within the focal plane of the grating), produced the largest amplitude responses at the center of the stimulus field and weaker responses in the periphery. These results are consistent with the anatomical position of this neuron in the most posterior region of the medulla and centered slightly ventral to the equator, which corresponds to medial retinotopic inputs shifted slightly dorsal to the equator of the compound eye. The timing of depolarizations relative to peaks in the photodetector record showed direction-dependent phase shifts, particularly during horizontal motion (Fig. $2 B$, vertical arrows). Such shifts, however, could arise from a slight difference between the receptive field of the cell and the position of the photodetector and therefore do not necessarily reflect a directionally selective response. In summary, the responses of this cell to flicker and motion are similar and show no clear evidence of directional motion information. Nevertheless, this neuron is in an 

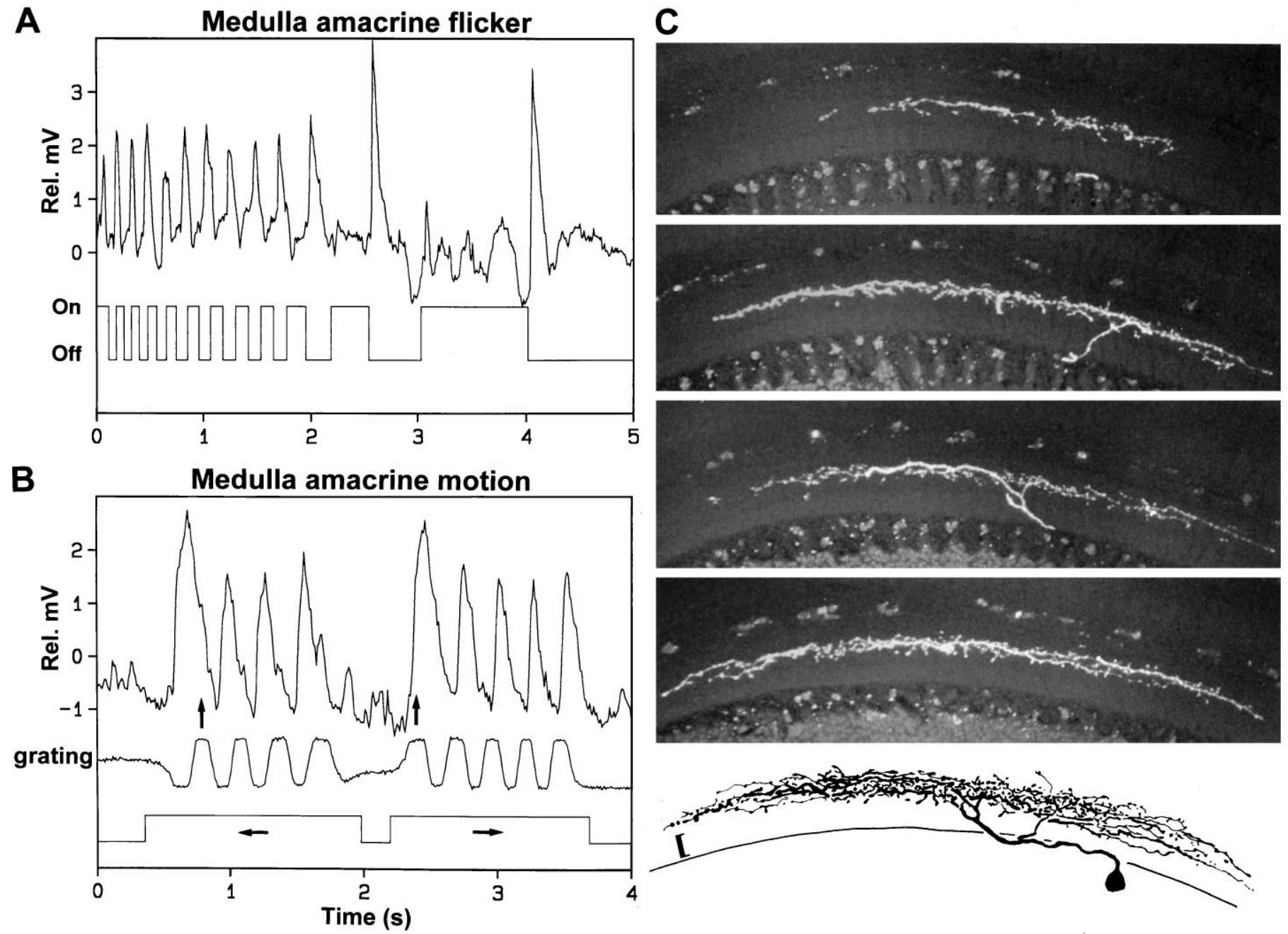

Figure 2. Intracellular recordings and anatomical reconstructions from a deep medulla amacrine. In $A$ and $B$, top traces show intracellular voltage relative to the prestimulus baseline $(O)$; bottom traces show the timing and duration of $(A)$ flicker On and Off and $(B)$ grating motion $($ arrows, motion direction). $B$, The middle trace records grating movements monitored at the center of the stimulus with a photodiode; vertical arrows illustrate the phase of grating motions relative to the intracellular responses. $C$, Confocal projections from four serial vertical sections through most of the medulla amacrine and reconstruction (bottom view) from the confocal projections. Ventral is to the left. Bracket indicates the T4 dendritic layer. The cell body lies within the chiasma between the medulla and the lobula complex. Magnification, $320 \times$.

ideal position to participate in elementary motion detection (see Discussion).

\section{T4-cells are nondirectionally selective retinotopic inputs to the lobula plate}

T4-cells are small-field retinotopic cells with finely branched dendritic trees along the proximal edge of the medulla and terminals usually restricted to one of the four directionally selective layers of the lobula plate. T4 and T5 neurons are indistinguishable at the light microscope level, except for the locations of their dendritic trees, respectively, in the proximal medulla and the outermost stratum of the lobula, facing the lobula plate (Fig. 1). In contrast to their morphological similarities, the physiological properties of T4- and T5-cells recorded thus far are strikingly different (see also Discussion). In short, T5-cells have fully developed directional selectivity characterized by excitatory and inhibitory responses to opposite motion directions, whereas T4 mainly exhibits depolarizations with very weak directional selectivity.

Successful intracellular recordings and stainings have been obtained from two T4-cells. In the first experiment (Fig. $3 A-C, G$ ), there is no question as to the identity of the neuron, because only one stable recording was obtained, and a single T4-cell (Fig. $3 C$ ) was filled with dye. Sparse, distal dendritic extensions beyond the main body of the dendritic tree (Fig. $3 C$ ) have not been noted previously in calliphorid flies but easily could be missed in Golgi preparations. At present it is uncertain whether this feature is representative of T4 morphology. In the second preparation (Fig. $3 D-F, G$ ) a few brief penetrations were followed by a more stable recording that was continued for several minutes before application of a hyperpolarizing current for $4 \mathrm{~min}$. Fluorescence microscopy revealed three stained cells: two T4 neurons within the same column and a third lightly stained neuron with its dendrites in the same column. Because one T4 neuron (Fig. $3 F, 1$ ) was by far the most brightly filled and the last impaled along the passage of the electrode, we conclude that this cell corresponds to the most stable recording. Both recorded T4-cells (Fig. 3A,D) responded to flicker with small, transient On depolarizations and very weak Off depolarizations. On depolarizations exhibited a latency of $\sim 15 \mathrm{msec}$, and the On responses decayed within $\sim 100$ msec. 
A

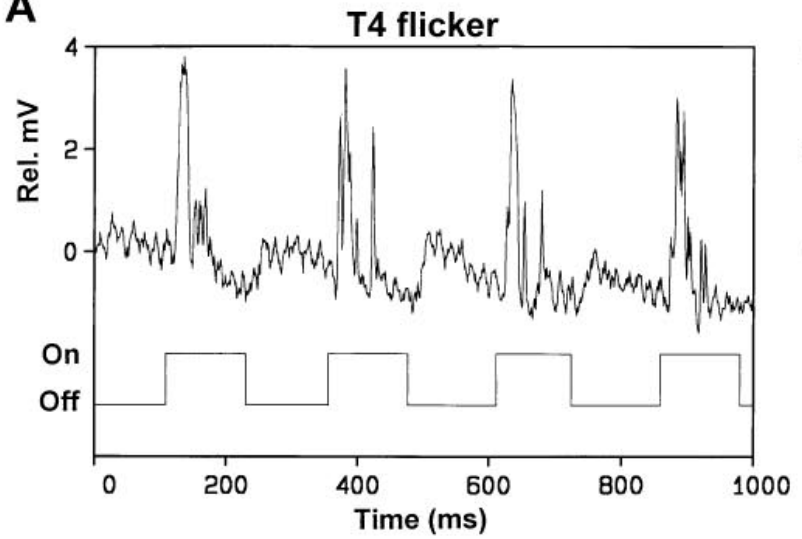

B

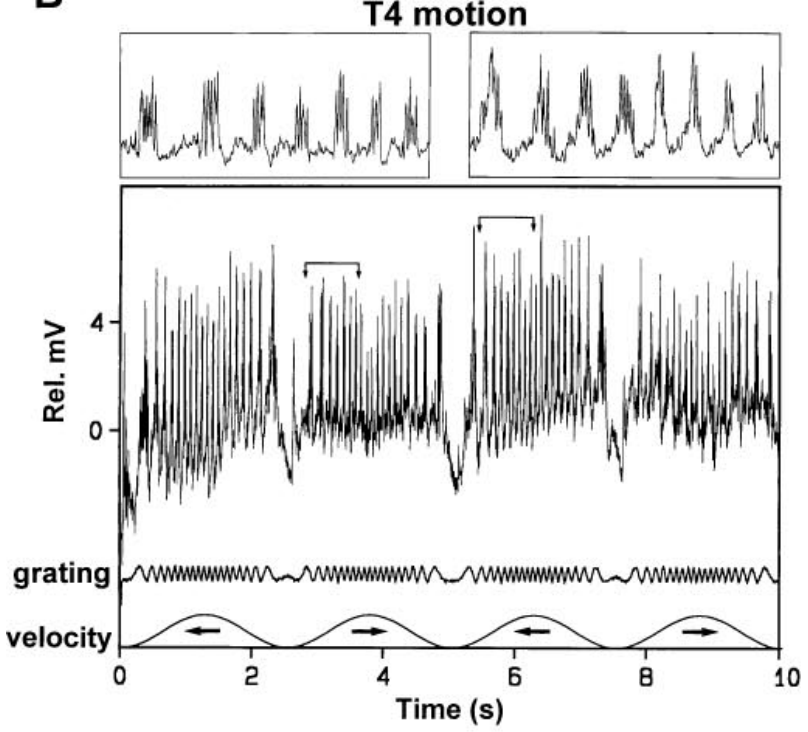

D

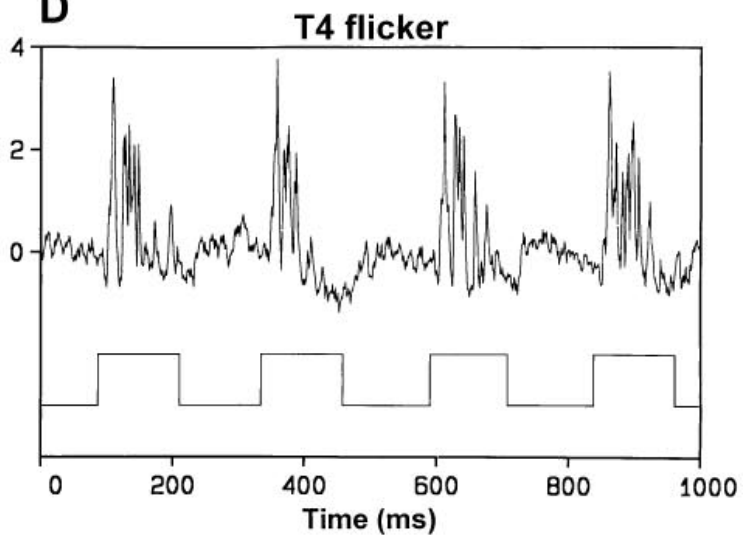

E

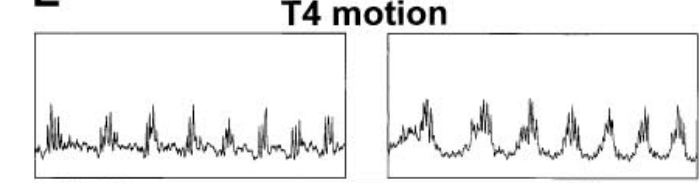

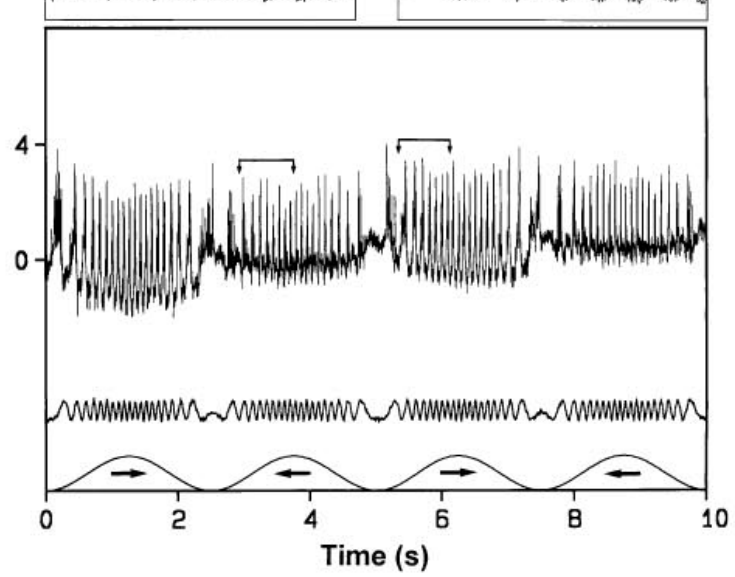

$C \Rightarrow$

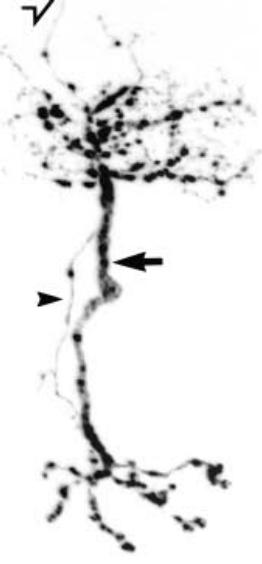

G

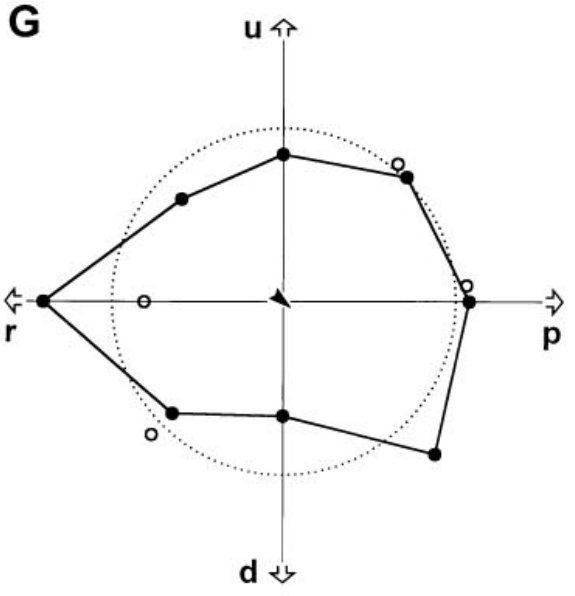

$\mathbf{F}$

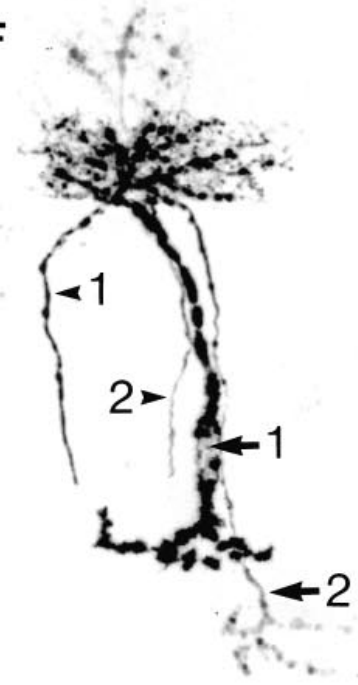

Figure 3. Flicker and motion responses of T4-cells from two separate preparations. Data in $A$ and $B$ are from the T4 neuron illustrated in $C$; $D$, $E$, Data from T4 neuron 1 in $F$. In $B$ and $E$, the top insets illustrate $800 \mathrm{msec}$ periods from the corresponding bracketed regions below them. Bottom traces show grating velocity, which was varied sinusoidally from 0 to $12 \mathrm{~Hz}\left(0\right.$ to $\left.93^{\circ} / \mathrm{sec}\right)$. $C$ and $F$, Reconstructions merged from confocal projections (negative images). Solid arrows, T4 axons; arrowheads, cell body fibers. Open arrow in $C$, Occasional processes extending toward the more distal stratum occupied by deep medulla amacrines. In $F$, solid arrow 1 shows the site of pipette penetration into the T4 axon. $G$, Responses to 4-8 grating motion directions ( $p$, progressive; $r$, regressive; $u$, upward; $d$, downward). Responses ( filled circles, T4 in $C$; open circles, T4 1 in $F$ ) were measured as the mean voltage difference between the peak depolarization and subsequent repolarization during the first 10 cycles of grating motion. For the T4 neuron in $C$, the dotted circle shows the mean response level ( $n=8$ directions; data from the second recording are normalized to this mean), and arrowhead shows mean response angle (324. $8^{\circ}$; vector length is negligible). Magnification in $C$ and $F, 970 \times$. 


\section{A $\quad$ 6 small-field responses}

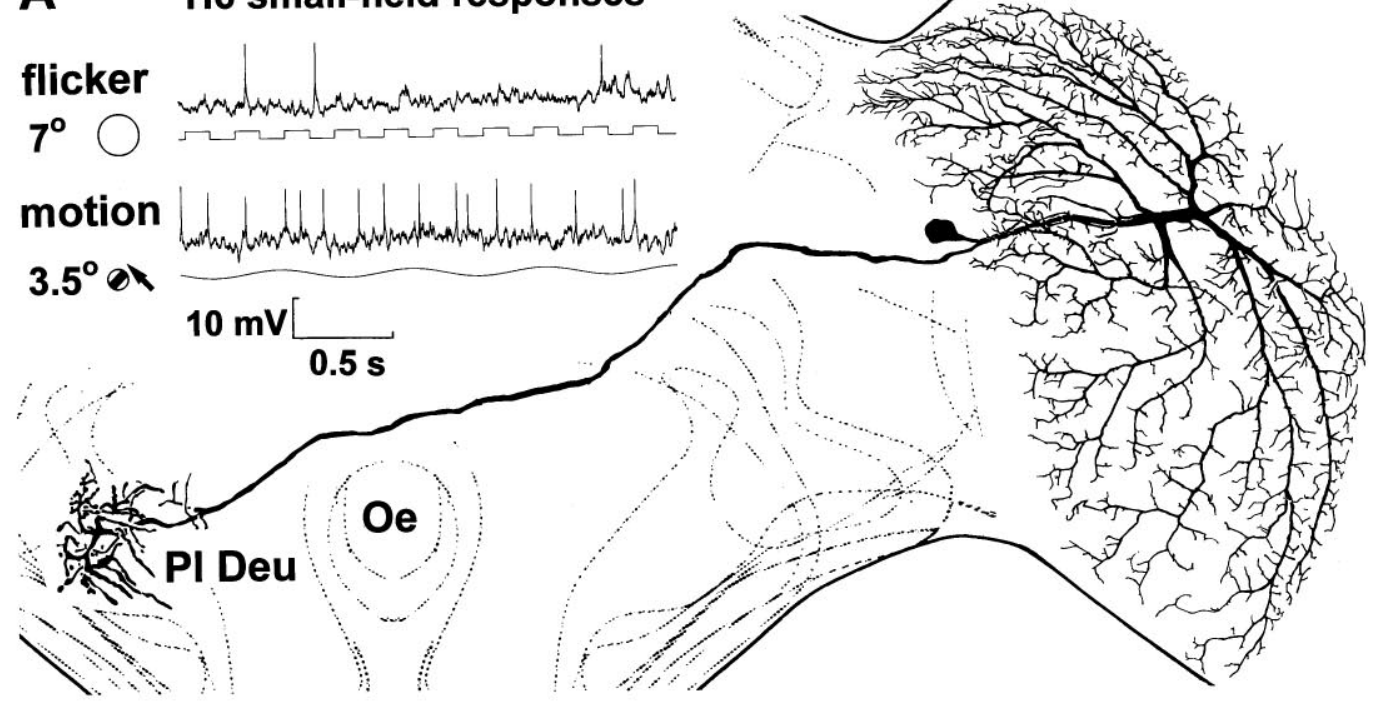

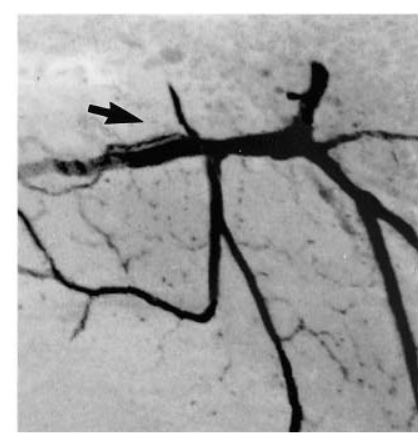

B

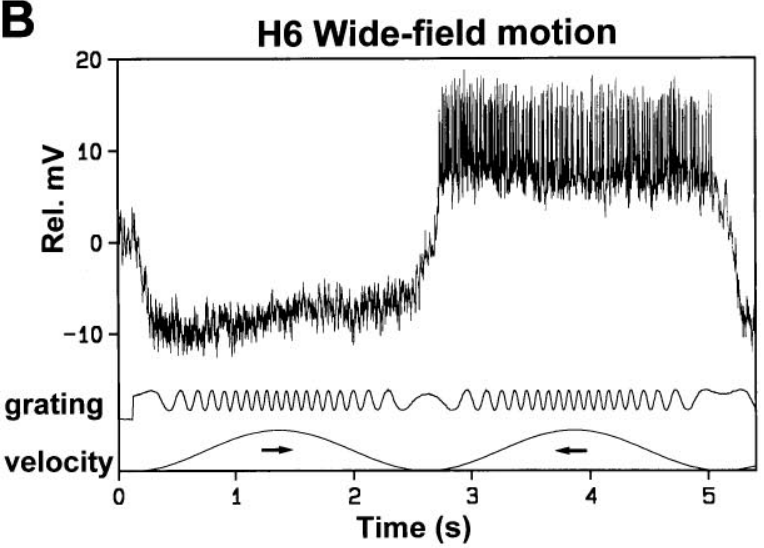

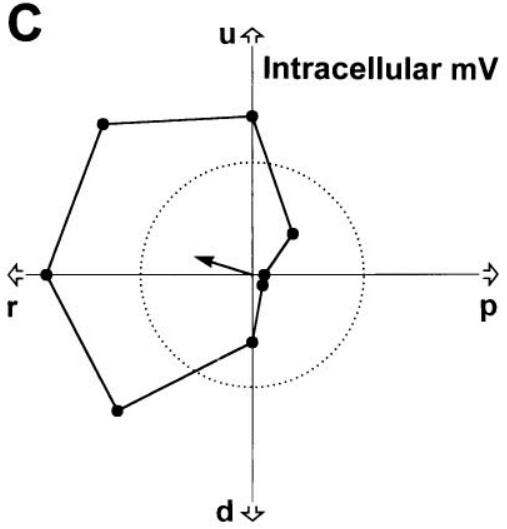

D<smiles>[2H][13CH3]</smiles>
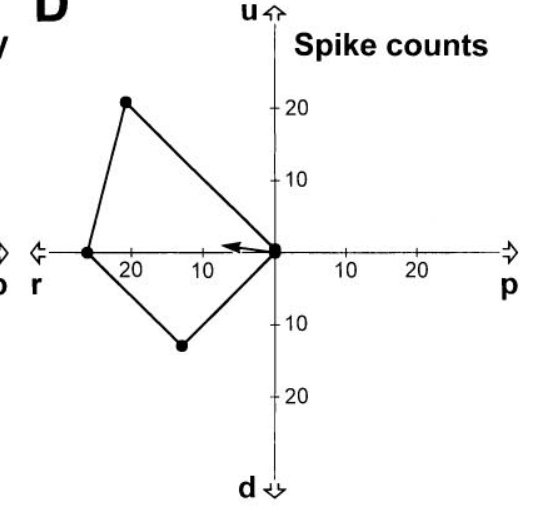

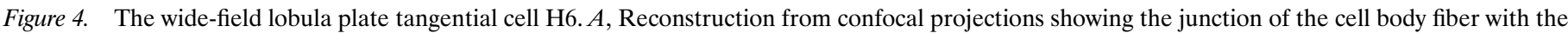

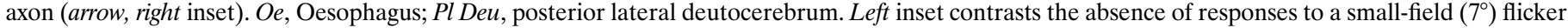

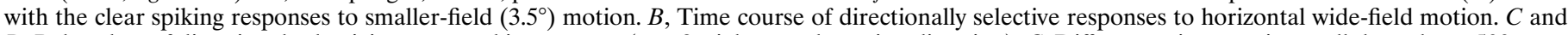

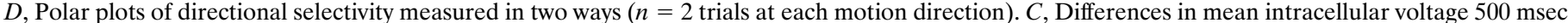

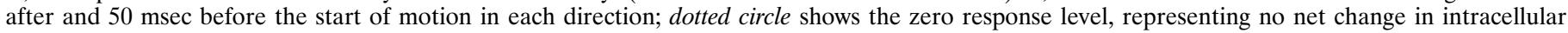

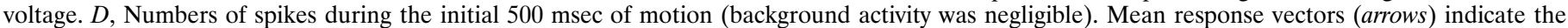

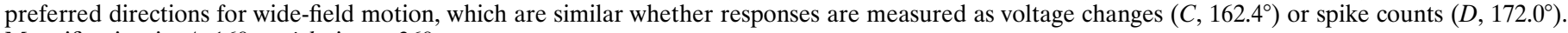
Magnification in $A, 160 \times$; right inset, $360 \times$.

The responses of T4 to horizontal motion (Fig. 3B,E) and all other directions (data not shown) were also flicker-like, consisting of trains of small transient depolarizations during each cycle of grating motion. Despite this overall similarity to flicker responses, some subtle changes in activity clearly were related to motion direction. The amplitudes of the transient depolarizations were weakly but consistently direction-dependent, as illustrated for horizontal motion in Figure 3. In addition, the larger amplitude transient depolarizations were accompanied by a slow hyperpolarization that occurred between the trains of depolarizations (Fig. 3B,E). Overall response amplitudes were quantified for different motion directions by measuring the maximum intracellular voltage difference between the depolarizing phase and the subsequent repolarized-hyperpolarized phase. Despite the clear presence of directional information in the raw data, the response amplitudes (Fig. 3G) show no significant directional trend. This result is in stark contrast to the strongly directional responses of T5 neurons (Douglass and Strausfeld, 1995).
It could be argued that directional responses may arise somewhere within $\mathrm{T} 4$ and could have been missed if the recordings were localized near the distal dendrites. The locus of pipette penetration, however, is visible in the confocal image of the second T4 as a hole near the end of the axon in the lobula plate (Fig. 3F, arrow 1). Additional arguments against a purely directional role for T4 neurons are considered in the Discussion.

\section{Collation of directionally selective motion channels}

H6 (Fig. 4) is a lobula plate tangential neuron that responds to directional motion (see below). Although the precise location of impalement could not be determined, the position of the pipette was in the lateral lobula plate. The dendritic field of H6 lies within the anterior, horizontally sensitive layer of the lobula plate (Buchner et al., 1984); its branches extend throughout the entire retinotopic projection from the medulla. The H6-cell body fiber meets the axon deep within the lobula plate (Fig. 4 A, right inset), and the axon projects above the esophagus and beneath the 
central body to reach the contralateral deutocerebrum. The terminal projections are located in the contralateral posterior slope of the brain among the axon collaterals of horizontal motionsensitive (HS) and vertical motion-sensitive (VS) cells and the dendritic trees of the centrifugal horizontal $(\mathrm{CH})$ cells (Hausen, 1981). Also in this region, numerous descending premotor neurons have their dendrites. Although both the physiological responses and general appearance of this neuron are similar to the H2 class of lobula plate tangentials (Hausen, 1984; Strausfeld et al., 1995), the morphology of H6 is sufficiently different that we consider it to be a uniquely identifiable neuron (see Discussion).

H6 exhibited robust spiking responses to motion and little background activity ( $\sim 0.1$ spikes/sec). This neuron appears to be more responsive to grating motion than to flicker, as indicated (Fig. $4 \mathrm{~A}$, left inset) by its clear spiking response to $3.5^{\circ}$ motion (mean spike rate $6.4 / \mathrm{sec}$ in figure), and the lack of response (1.2 spikes/sec) to a larger $\left(7^{\circ}\right)$ flicker stimulus at the same location and having the same flux density. H6 was particularly sensitive, however, to wide-field motion (Fig. $4 B$ ). Regressive motion produced sustained spiking $(62.5 / \mathrm{sec})$ superimposed on a DC depolarization, whereas progressive motion resulted in a sustained hyperpolarization and completely inhibited the spiking. These responses were used to evaluate the directional selectivity of H6 to wide-field motion in two ways, as changes in average membrane voltage and in spiking activity during the first $500 \mathrm{msec}$ of motion. Both measures (Fig. 4C,D) demonstrate strongest excitation during wide-field regressive motion directed slightly upward.

Additional, qualitative tests employing small-field (3.5 ), regressive-upward grating motion suggested that the $\mathrm{H} 6$ receptive field includes a broad region of the ipsilateral visual field. Similarly, horizontal regressive motion of a single vertical bar (black or white on a gray background) produced strong spiking responses as long as the bar was moving within the ipsilateral visual field. The angular extent of these stimuli, however, was limited to the $40 \times$ $50^{\circ}$ view the fly had of the stimulus screen. On the basis of the dendritic morphology of H6, its full receptive field may encompass the entire ipsilateral visual field.

\section{Centrifugal pathways from lobula plate to medulla}

Y-cells (Strausfeld and Blest, 1970) are characterized by arborizations in the medulla, lobula, and lobula plate. Most Y-cells described from Golgi impregnations have their cell bodies situated distally, above the medulla, and are considered to be centripetal neurons (Strausfeld, 1976). Only a few Y-cells in flies have been reported with proximal cell bodies [Y5, Y18, and Y19 in Strausfeld (1976) and Y1 and Y3-Y6 in Fischbach and Dittrich (1989) using a different numbering system]; the perikarya of these neurons are all located behind the lobula plate. To our knowledge, the only physiological recording identified with a Y-cell of this class is from a Y18-like neuron, which showed nondirectionally selective responses to motion (Gilbert et al., 1991). Here, we describe two new Y-cells of this class that, because established morphological criteria suggest centrifugal connections from the lobula plate to the medulla (see below), we refer to as centrifugal Y- (CY) cells. As an example, CY1 (Fig. 5A) was filled with Lucifer yellow but yielded no usable physiological data. Its dendrites invade a narrow zone of the lobula plate, penetrating all four motion-sensitive layers but spreading laterally in the shallow horizontal layer and the deep vertical layer. The neuron provides two axonal processes that ascend to an equivalent retinotopic location in the medulla, proximal to the serpentine layer, and two axon collaterals (one from each process) that penetrate equivalent retinotopic positions in the lobula. The medulla terminals are so-called because of their typical varicose and beaded profiles, which are indicative of presynaptic sites (Strausfeld and Bassemir, 1985). The same features characterize the lobula collaterals, suggesting centripetal connections from the lobula plate.

A second species of centrifugal Y-cell is shown in Figure $5 B$. This neuron, termed CY2, has extensive tangential arborizations with numerous dendritic spines in the lobula plate. Terminals in the medulla are all proximal to the serpentine layer. The arborizations in the lobula plate occupy a small region that corresponds to frontomedial retinotopic inputs, in good agreement with qualitative tests of the receptive field for flicker. The lobula plate arborizations are split into two tangentially oriented layers, the first within the HS layer of the neuropil and the second in the VS layer and displaced dorsally by approximately five retinotopic columns. Thus, CY2 combines HS and VS inputs that are also retinotopically distinct. The axon bifurcates to penetrate the distal lobula and proximal medulla, arrayed tangentially and vertically in both cases through a range of approximately five columns. As in CY1, the projections of this cell into the medulla and lobula are varicose and sparsely branched, suggesting that these two components consist mainly of presynaptic terminals and that the lobula plate processes, which are spined, are the principal input region.

A comparison of the flicker latencies of CY2- and T4-cells is consistent with this conclusion. The responses of CY2 to a $7^{\circ}$ diameter flicker stimulus (Fig. 5C) were transient depolarizations with variable timing during the On phase of the stimulus. A peristimulus time average of the illustrated flicker responses (Fig. $5 C$, inset; $n=8$ ) shows a tendency for Off depolarizations to have larger amplitudes and shorter mean latencies $(23.5 \mathrm{msec}$, measured to the start of depolarization) than the On depolarizations (mean latency $44.5 \mathrm{msec}$ ). The On latency is quite long, compared with a mean of 15.4 msec measured from T4-cells tested with the same stimulus (data from Fig. $3 A, D ; n=8$ ). Notwithstanding possible discrepancies in conduction times, such a large difference in flicker delays suggests that $\mathrm{CY} 2$ receives its main inputs at a higher level of processing than T4-cells.

CY2 showed tonic, nonspiking, directionally selective responses to motion. The strongest depolarizations were to progressive and upward motion, with somewhat weaker hyperpolarizations during regressive and downward motion (Fig. 5D,E). In addition to its directional selectivity, CY2 seems to be strongly influenced by the temporal properties of grating motion (contrast frequency or angular velocity). During progressive motion, the level of depolarization was positively correlated with stimulus speed (Fig. 5D). During upward motion, in contrast (Fig. 5E), depolarization levels were relatively stable except at higher speeds at which partial repolarizations were observed. Responses to progressive upward motion (data not shown) were approximately intermediate between these two patterns, showing fairly steady depolarization through most of the $0-12 \mathrm{~Hz}$ range of contrast frequencies tested. Although sinusoidally varying the motion speed provides a wealth of information within a short recording time, the responses to different motion speeds are not independent and should be interpreted with caution. Nevertheless, these results suggest a greater sensitivity to motion speed in CY2 than in either H6 or T4 neurons.

As in the analysis of $\mathrm{H} 6$ responses (Fig. $4 C$ ), the directional selectivity of $\mathrm{CY} 2$ was evaluated by computing the difference between the baseline membrane voltage and the mean voltage during the initial $500 \mathrm{msec}$ of motion. Examination of the raw data suggested the presence of significant response latencies to motion, 
A
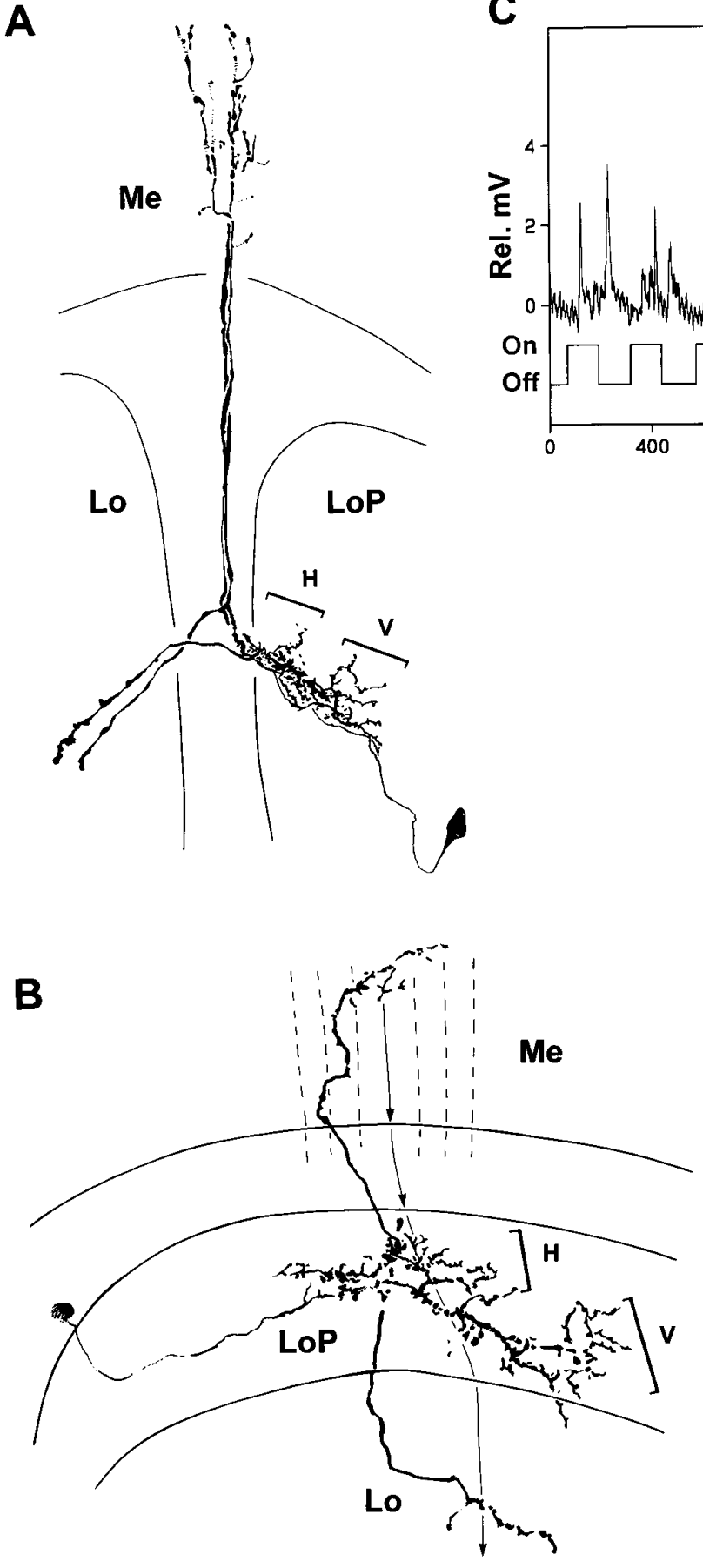

C
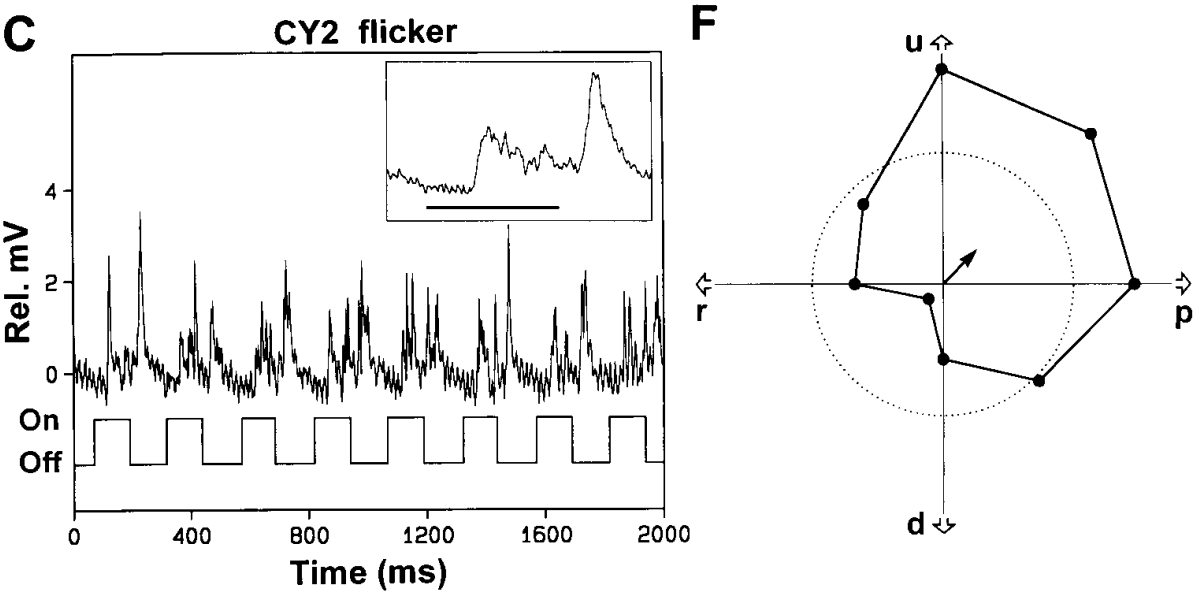

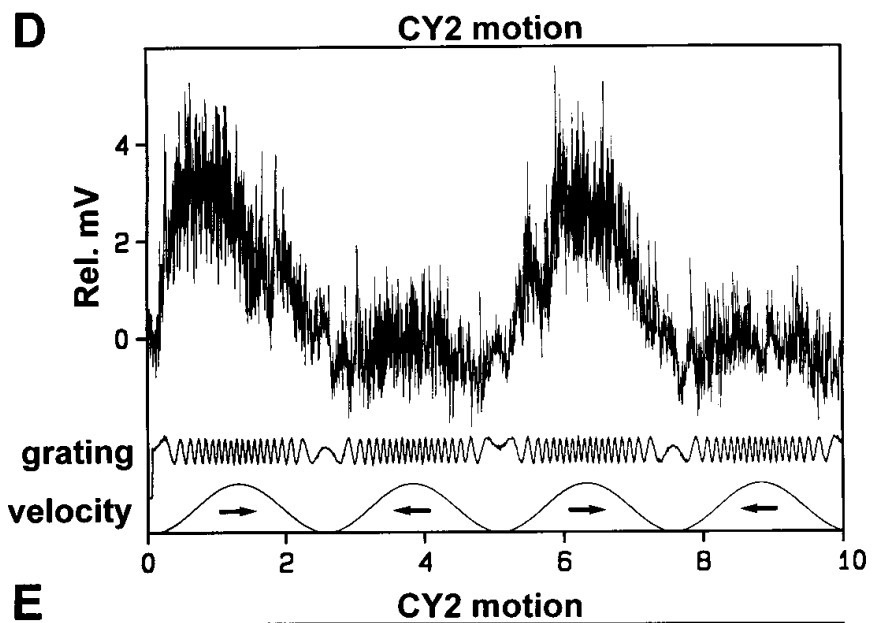

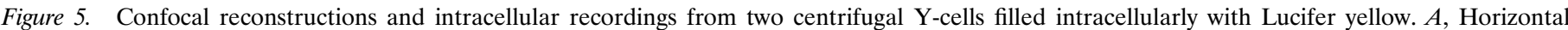

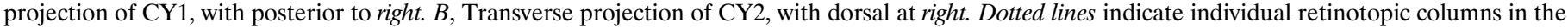

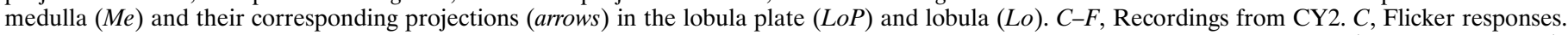

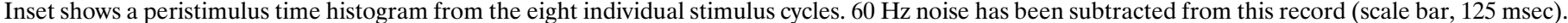

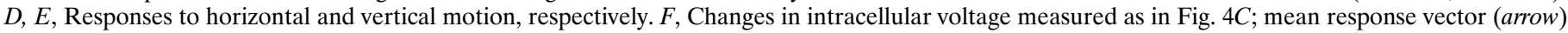
$=45.2^{\circ}$. Magnification in $A$ and $B, 390 \times$.

consistent with the relatively long flicker latencies noted above for this cell. Analyses performed over a range of possible response latencies (0-150 msec), however, showed no major effect on the overall pattern of directional selectivity. The polar plot in Figure $5 F$ assumes a response latency of $38 \mathrm{msec}$, which is intermediate between the measured latencies to flicker On and Off. The mean response vector indicates a preference for combined progressive and upward motion in this neuron.

\section{DISCUSSION}

This paper describes intracellular recordings from identified neurons that, even based solely on their anatomical relationships 
within the optic lobe (Boscheck, 1971; Hausen, 1984; Strausfeld and Lee, 1991; Douglass and Strausfeld, 1995; Buschbeck and Strausfeld, 1996), seem likely to be important for processing visual motion. Three of these neurons, H6, CY1, and CY2, previously have not been observed, and though $\mathrm{T} 4$ is well known from anatomical studies as a crucial small-field retinotopic input to the lobula plate, the present recordings provide the first direct answers to longstanding questions surrounding the functional properties of this neuron.

\section{Lobula plate tangential neurons collate but do not detect elementary motion}

Because H6 shares certain characteristics with several other calliphorid lobula plate tangential cells, its designation as a new, uniquely identifiable cell requires careful justification. H6 has a large dendritic field in the lobula plate, terminal arborizations in the contralateral posterior slope of the brain, and directional selectivity to horizontal motion. This general description also fits H2-H5 (Hausen, 1984; Hausen and Egelhaaf, 1989; Strausfeld et al., 1995) and the figure detection neuron FD4 (Egelhaaf, 1985). All but $\mathrm{H} 2$, however, are eliminated from further consideration by major differences in dendritic morphology (H3-H5, FD4), the presence of axon collaterals in the ipsilateral deutocerebrum $(\mathrm{H} 3$, H4), or a preferred direction opposite to that of H6 (H3, FD4).

What, then, distinguishes H6 from H2? Although both cells share a similar morphology, are excited by regressive motion, and are inhibited by progressive motion, they nevertheless differ in important details. First, the H6 dendritic field fills the entire lobula plate (Fig. 4A), whereas in two independent reconstructions of H2 (Hausen, 1984; Strausfeld et al., 1995), dendrites are absent from large ventromedial and dorsomedial portions of the neuropil. The H6 cell body fiber and all of the dendritic branches originate in the lateral half of the lobula plate (Fig. $4 A$ ), whereas some $\mathrm{H} 2$ dendrites arise within the medial half of the neuropil, and the cell body fiber arises proximal to the lobula plate. Arguably, these differences may reflect interspecific or intraspecific variation, because the available illustrations of $\mathrm{H} 2$ are from Calliphora or Sarcophaga (Hausen, 1984; Strausfeld et al., 1995), whereas H6 was recorded from Phaenicia. Comparisons among calliphorid VS cells (Phaenicia, Calliphora, and Sarcophaga), however, show consistency in the major branching patterns and in patterns of dendritic field coverage (Eckert and Bishop, 1978; Hengstenberg et al., 1982). Thus, the differences noted here between $\mathrm{H} 2$ and $\mathrm{H} 6$ are expected to reflect reliable distinguishing features.

There is also evidence for physiological differences between these two neurons. $\mathrm{H} 2$ clearly demonstrates excitatory On and Off responses to stimulation with wide-field flicker (Strausfeld et al., 1995). In contrast, H6 (Fig. $4 A$, left inset) produced spikes in response to small-field motion but no clear response to a significantly larger flicker stimulus. Finally, H6 physiology also differs significantly from that of FD cells. The diagnostic functional feature of FD neurons is that they have stronger responses to small object motion than to wide-field motion (Egelhaaf, 1985). H6, however, responded far less vigorously to small-field than to wide-field gratings in the same direction (Fig. 4). Presumably, small object motion also would produce weak responses.

Despite their morphological differences, the general functional role of $\mathrm{H} 6$ seems similar to that of $\mathrm{H} 2$, namely to report to the contralateral brain the presence of wide-field, regressive horizontal motion. What is the relative importance of spikes and graded potential changes in relaying directional information from $\mathrm{H} 6$ to its postsynaptic targets? Because of the distances involved and the fairly small axon diameter of $\mathrm{H} 6$, graded potential changes in the dendrites probably have no direct influence upon its postsynaptic targets, but they may contribute to the relatively narrow directional tuning of the spiking response (compare Fig. $4 C$ and $D$ ) by inhibiting spike generation during null direction motion.

\section{Retinotopic, directionally selective feedback from the lobula plate}

Lobula plate centrifugal Y neurons similar to the CY cells described here (Fig. 5) have been reported in Golgi preparations from Drosophila, in which dendrites in the lobula plate extend across all four directional layers, and terminals are restricted to the medullary strata proximal to the serpentine layer and to the outer lobula strata (Fischbach and Dittrich, 1989). Although the morphology of CY2 is somewhat similar to the centrifugal Y1-cell in Drosophila (Fischbach and Dittrich, 1989), the latter neuron has wider and more extensive lobula plate arborizations. Thus, the small-field, bistratified displaced dendrites of CY2 designate it as a novel cell type.

CY1 and CY2 neurons are intriguing from a computational standpoint because they may provide both feedback inputs to the proximal medulla and feed-forward to equivalent retinotopic locations in the lobula. The basic responses of CY2 to motion, noisy graded depolarizations or weak hyperpolarizations, are similar to responses of HS and VS neurons in the lobula plate. Significantly, the lobula plate arborizations are divided into two parts, one in the horizontal motion-sensitive layer and a second, retinotopically displaced, portion in the vertically sensitive layer. This arrangement, on a small scale, is analogous to the VH neuron and VS 1 neuron, both wide-field centripetal cells in the lobula plate that have bistratified dendritic fields and show hybrid physiological properties of HS and VS neurons (Eckert and Bishop, 1978; Eckert, 1982; Hengstenberg et al., 1982). Similarly, and as expected from the morphology, the preferred direction of CY2 was a combination of progressive and upward motion (Fig. $5 F$ ).

\section{The deep medulla amacrine}

The deep medulla amacrine is a newly identified neuron, possibly homologous to m:tan5 in the drone fly Eristalis tenax (Strausfeld, 1970). The amacrine recorded here has been observed often in Golgi preparations of Phaenicia and is revealed clearly by antibodies against the inhibitory neurotransmitter GABA (M.C. Anderson and N.J. Strausfeld, unpublished observations).

This neuron exhibited transient depolarizations in response to flicker Off and during motion but with no clear directional component. Its layer relationships with other neurons suggest that this amacrine could be an essential part of elementary motiondetecting circuits. The arborizations just distal to the T4 dendritic layer are ideally situated for lateral connections among small-field retinotopic transmedullary neurons such as Tm1 (Strausfeld and Lee, 1991; Buschbeck and Strausfeld, 1996), the axon collaterals of which coincide with the deep medulla amacrine layer. Tm1 is capable of directionally selective responses to motion (Douglass and Strausfeld, 1995), but it is unknown whether directional selectivity arises presynaptic to or within Tm1. If a Tm1 is integral to each EMD, then the lateral connections essential to any EMD circuit could be embodied in pre- and postsynaptic interactions between the deep medulla amacrine and the Tm1 collaterals.

The proposal that the deep medulla amacrine may participate in elementary motion detection suggests possible analogies with motion-detecting circuitry in vertebrates. In the rabbit, responses 
of directionally selective ganglion cells can be explained by a combination of the morphological asymmetry between starburst amacrine input and output connections (Famiglietti, 1983; Brandon, 1987; Wässle and Boycott, 1991), an interplay between excitatory and delayed inhibitory interactions, and relative electrical isolation of individual dendritic branches from the remainder of the cell (Vaney, 1990; Borg-Graham and Grzywacz, 1992; Grzywacz et al., 1995). In the fly brain, the GABAergic deep medulla amacrine could play a similar role, with the more distal portions of Tm1 corresponding to bipolar-like inputs and the proximal projections of Tm1 corresponding to directionally selective ganglion cells. It will be important to learn whether deep medulla amacrines share additional features with starburst amacrines and to learn about the nature of their synaptic interconnections with Tm1-cells.

\section{Historical evidence that T4 processes directional motion}

What functional role, if any, does T4 play in motion processing? Historically, anatomical and physiological evidence has favored a major role for both $\mathrm{T} 4$ and $\mathrm{T} 5$ in directional motion processing and has underpinned reasoned speculation that they themselves are components of EMDs (Hausen and Egelhaaf, 1989; Strausfeld, 1989; Gilbert, 1990). T4 and T5 axons, respectively, form the only exclusive retinotopic projections to the lobula plate from the medulla and its displaced layer in the lobula. The first clearly directional responses to motion arise in the medulla (Devoe, 1980; Douglass and Strausfeld, 1995), and the lobula plate is well known as a major center for directional motion processing and figure-ground discrimination. Golgi- and cobalt-stained material demonstrates that T4 and T5 terminals are closely apposed to HS and VS dendrites in the lobula plate, and ultrastructural observations have confirmed output synapses from T4 to HS (Strausfeld and Lee, 1991). The terminal arborizations of individual T4 and T5 neurons generally are restricted to one of four layers (Fischbach and Dittrich, 1989; Strausfeld, 1989) that contain the dendrites of DS lobula plate tangential neurons and that correspond to upward-, downward-, regressive-, and progressive-preferred directions (Dvorak et al., 1975; Eckert, 1980; Hengstenberg et al., 1982). Finally, there are four T4 axons and at least two T5 axons per retinotopic column (Strausfeld and Lee, 1991), suggesting that each retinotopic column contains a bushy T-cell that terminates in one of the four directionally selective layers in the lobula plate. These observations strongly implicate both T4 and T5 in directional motion processing.

\section{Evidence that T4 does not process directional motion}

The first suggestion that T4 might not be directionally selective (Douglass and Strausfeld, 1995) was provided by intracellular recordings from $\mathrm{T} 5$, its presumed sole input $\mathrm{Tm} 1$, and $\mathrm{iTm}$, the equivalent input to T4 (Strausfeld and Lee, 1991; Buschbeck and Strausfeld, 1996). Although all three types of neurons responded differently to motion and flicker, directionally selective responses were demonstrated only in Tm1 and T5. Thus, both elementary motion detection and the delivery of directional motion signals to the lobula plate can be accomplished without invoking T4 at all.

The present recordings strongly support the idea that $\mathrm{T} 4$ does not process directional motion, despite the paradoxical presence of weak directional signals in T4. If viewed in isolation from the robust directional selectivity of $\mathrm{T} 5$, one might interpret the weakly directional T4 signals as evidence of an early stage in elementary motion detection. However, because directional motion detection

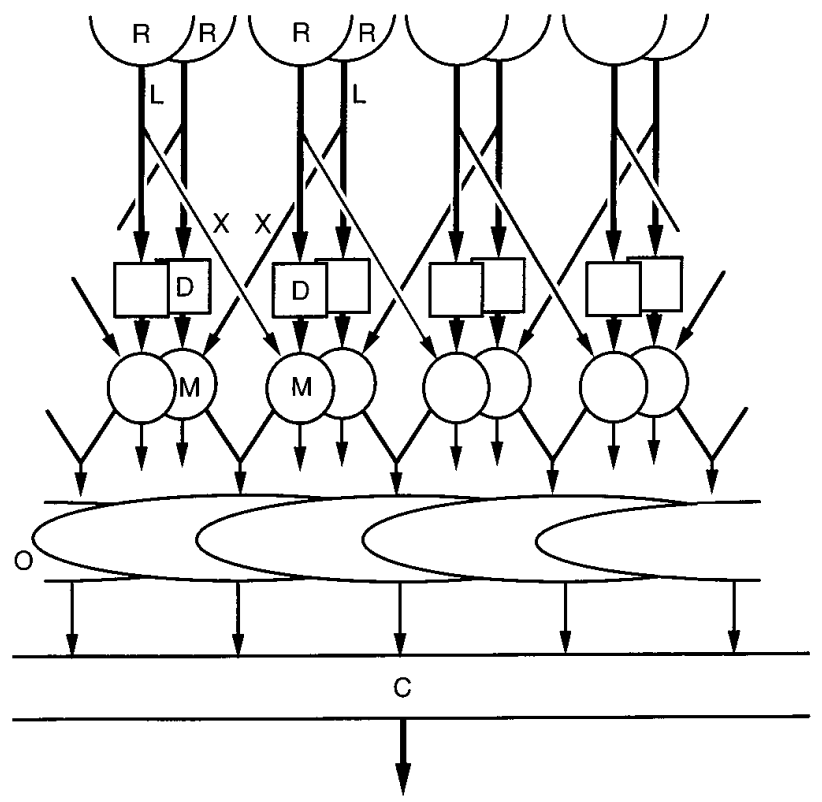

Figure 6. Hypothetical circuit diagram yielding nondirectional, motionspecific outputs from inherently directional, correlation-type elementary motion detectors (EMDs). $R$, Receptor; $L$, first-order relay; $X$, connector between neighboring channels; $D$, delay or long-pass filter; $M$, integrator; $O$, second integrating stage that combines outputs of individual directionally selective EMDs to provide a nondirectional, motion-specific summation (compare Fig. 12 in Douglass and Strausfeld, 1995); $C$, collator neuron (lobula plate tangential cell) that collects from assemblies of second integrators. A circuit such as this provides a possible explanation for the weakly directional motion responses observed in T4-cells, without invoking separate EMD mechanisms for T4 and T5. See Discussion.

has already been accomplished at the Tm1 level or earlier (Douglass and Strausfeld, 1995) and because there is no known need for a second EMD mechanism in the medulla, the functional utility of directional selectivity in T4 is questionable. An alternative role for $\mathrm{T} 4$ is to convey nondirectional information to the lobula plate. In this case, any accompanying weak directional signal may merely reflect contamination, for example from indirect synaptic interactions with neighboring DS elements. Finally, suppose that T4 is part of a retinotopic-labeled line that conveys nondirectional yet motion-specific information. If the only motion detectors available are inherently directional, then it is necessary to attenuate the directionality of those signals. This could be accomplished simply by combining the outputs from individual EMDs having opposite preferred directions (Fig. 6); unless the attenuation were perfect, some residual directional selectivity would remain.

For any complete description of motion, both speed and direction must be evaluated. Behavioral experiments demonstrate that insects are capable of estimating both parameters, yet certain visually guided responses rely primarily on one parameter in isolation from the other. Optomotor responses clearly are tuned to directional cues, but the directional information is easily corrupted by changes in temporal frequency or spatial structure (Götz, 1965; for review, see Reichardt, 1987; Borst and Egelhaaf, 1989). In contrast, distance computations in peering locusts rely on direction-insensitive motion-detecting mechanisms (Sobel, 1990), whereas centering responses of bees use estimates of apparent angular speed and are relatively insensitive to contrast frequency (Srinivasan et al., 1991). These experiments all suggest 
that separate, parallel pathways process directional and nondirectional motion, a conclusion that receives additional support from direct comparisons of direction-sensitive optomotor responses with speed-sensitive centering responses (Srinivasan et al., 1993). We suggest that the T4 and T5 pathways may represent a major portion of the neuroanatomical substrates for these two parallel pathways.

\section{REFERENCES}

Bausenwein B, Fischbach K-F (1992) Separation of functional pathways in the fly's medulla: combination of 2-deoxyglucose studies with anatomical fine analysis. In: Nervous systems: principles of design and function (Singh RN, ed), pp 223-239. New Delhi, India: Wiley Eastern.

Borg-Graham LJ, Grzywacz NM (1992) A model of the directional selectivity circuit in retina: transformations by neurons singly and in concert. In: Single neuron computation (McKenna T, Zornetzer SF, eds), pp 347-375. Boston, MA: Academic.

Borst A, Egelhaaf M (1989) Principles of visual motion detection. Trends Neurosci 12:297-306.

Boschek CB (1971) On the fine structure of the peripheral retina and the lamina of the fly, Musca domestica. Z Zellforsch Mikrosk Anat 110:336-349.

Braitenburg V, Taddei Ferretti C (1966) Landing reaction of Musca domestica induced by visual stimuli. Naturwissenschaften 53:155.

Brandon C (1987) Cholinergic neurons in the rabbit retina: dendritic branching and ultrastructural connectivity. Brain Res 426:119-130.

Buchner E (1976) Elementary movement detectors in an insect visual system. Biol Cybern 24:85-101.

Buchner E, Buchner S, Bülthoff I (1984) Deoxyglucose mapping of nervous activity induced in Drosophila brain by visual movement. I. Wildtype. J Comp Physiol [A] 155:471-483.

Buschbeck EK, Strausfeld NJ (1996) Visual motion detection circuits in flies: small-field retinotopic elements responding to motion are evolutionarily conserved across taxa. J Neurosci 16:4563-4578.

Collett TS, Land MF (1978) How hoverflies compute interception courses. J Comp Physiol 125:191-204.

DeVoe RD (1980) Movement sensitivities of cells in the fly's medulla. J Comp Physiol 138:93-119.

DeVoe RD, Ockleford EM (1976) Intracellular responses from cells of the medulla of the fly, Calliphora erythrocephala. Biol Cybern 23:13-24.

Douglass JK, Strausfeld NJ (1995) Visual motion detection circuits in flies: peripheral motion computation by identified small-field retinotopic neurons. J Neurosci 15:5596-5611.

Dvorak DR, Bishop LG, Eckert HE (1975) On the identification of movement detectors in the fly optic lobe. J Comp Physiol 100:5-23.

Eckert H (1980) Functional properties of the H1 neuron in the third optic ganglion of the blowfly, Phaenicia. J Comp Physiol 135:29-39.

Eckert H (1982) The vertical-horizontal neurone (VH) in the lobula plate of the blowfly, Phaenicia. J Comp Physiol 149:195-205.

Eckert H, Bishop LG (1978) Anatomical and physiological properties of the vertical cells in the third optic ganglion of Phaenicia sericata (Diptera, Calliphoridae). J Comp Physiol 126:57-86.

Egelhaaf M (1985) On the neuronal basis of figure-ground discrimination by relative motion in the visual system of the fly. II. Figure detection cells, a new class of visual interneurones. Biol Cybern 52:195-209.

Egelhaaf M, Hausen K, Reichardt W, Wehrhahn C (1988) Visual course control in flies relies on neuronal computation of object and background motion. Trends Neurosci 11:351-358.

Famiglietti EV (1983) ON and OFF pathways through amacrine cells in mammalian retina: the synaptic connections of "starburst" amacrine cells. Vision Res 23:1265-1279.

Fischbach K-F, Dittrich APM (1989) The optic lobe of Drosophila melanogaster. I. A Golgi analysis of wild-type structure. Cell Tissue Res 258:441-475.

Franceschini N, Riehle A, Le Nestour A (1989) Directionally selective motion detection by insect neurons. In: Facets of vision (Stavenga DG, Hardie RC, eds), pp 360-390. Heidelberg: Springer.

French AS, Järvilehto M (1978) The transmission of information by first and second order neurons in the fly visual system. J Comp Physiol 126:87-96.

Gilbert C (1990) Membrane conductance changes associated with the response of motion-sensitive insect visual neurons. Z Naturforsch 45C:1222-1224.
Gilbert C, Penisten DK, DeVoe RD (1991) Discrimination of visual motion from flicker by identified neurons in the medulla of the fleshfly Sarcophaga bullata. J Comp Physiol [A] 168:653-673.

Götz KG (1965) Behavioral analysis of the visual system of the fruitfly Drosophila. In: Information processing in sight sensory systems, pp. 85-99. Pasadena, CA: California Institute of Technology.

Grzywacz N, Sernagor E, Amthor FR (1995) Directional selectivity in the retina. In: The handbook of brain theory and neural networks (Arbib MA, ed), pp 312-314. Cambridge, MA: MIT.

Hassenstein B, Reichardt W (1956) Systemtheoretische Analyse der Zeit-, Reihenfolgen-, und Vorzeichenauswertung bei der Bewegungsperzeption des Rüsselkäfers Chlorophanus. Z Naturforsch 11:513-524.

Hausen K (1981) Monocular and binocular computation of motion in the lobula plate of the fly. Verh Dtsch Zool Ges 1981:49-70.

Hausen K (1984) The lobula complex of the fly: structure, function, and significance in visual behavior. In: Photoreception and vision in invertebrates (Ali MA, ed), pp 523-599. New York: Plenum.

Hausen K, Egelhaaf M (1989) Neural mechanisms of visual course control in insects. In: Facets of vision (Stavenga DG, Hardie RC, eds), pp 391-424. Berlin: Springer.

Hengstenberg R (1993) Multisensory control in insect oculomotor systems. Rev Oculomot Res 5:285-298.

Hengstenberg R, Hausen K, Hengstenberg B (1982) The number and structure of giant vertical cells (VS) in the lobula plate of the blowfly Calliphora erythrocephala. J Comp Physiol 149:163-177.

Kaiser W (1975) The relationship between visual movement detection and colour vision in insects. In: The compound eye and vision of insects (Horridge GA, ed), pp 359-377. Oxford: Clarendon.

Kaiser W, Liske E (1974) Die optomotorischen Reaktionen von fixiert fliegenden Bienen bei Reizung mit Spektrallichtern. J Comp Physiol 80:391-408.

Kirchner WH, Srinivasan MV (1989) Freely flying honeybees use image motion to estimate object distance. Naturwissenschaften 76:281-282.

Land MF (1992) Visual tracking and pursuit: humans and arthropods compared. J Insect Physiol 38:939-951.

Laughlin S (1981) Neural principles in the peripheral visual systems of invertebrates. In: Comparative physiology and evolution of vision in invertebrates. Handbook of sensory physiology Vol VII/6B (Autrum H, ed), pp 133-280. Berlin: Springer.

Lehrer M (1994) Spatial vision in the honeybee: the use of different cues in different tasks. Vision Res 34:2363-2385.

Lehrer M, Srinivasan MV (1992) Freely flying bees discriminate between stationary and moving objects: performance and possible mechanisms. J Comp Physiol [A] 171:457-467.

Livingstone MS, Hubel DH (1988) Segregation of form, color, movement, and depth: anatomy, physiology, and perception. Science 240:740-749.

Maunsel JHR, Newsome WT (1987) Visual processing in monkey extrastriate cortex. Annu Rev Neurosci 10:363-401.

Menzel R (1973) Spectral responses of moving detecting and "sustaining" fibres in the optic lobe of the bee. J Comp Physiol 82:135-150.

Reichardt W (1987) Evaluation of optical motion information by motion detectors. J Comp Physiol [A] 161:533-547.

Riehle A, Franceschini N (1982) Response of a directionally selective movement detecting neuron under precise stimulation of two identified photoreceptor cells. Neurosci Lett Suppl 10:5411-5412.

Sobel E (1990) The locust's use of motion parallax to measure distance. J Comp Physiol [A] 167:579-588.

Spurr AR (1969) A low viscosity embedding medium for electron microscopy. J Ultrastruct Res 26:31-43.

Srinivasan MV, Guy RG (1990) Spectral properties of movement perception in the dronefly Eristalis. J Comp Physiol [A] 166:287-295.

Srinivasan MV, Lehrer M (1984) Temporal acuity of honeybee vision: behavioural studies using moving stimuli. J Comp Physiol [A] 155:297-312.

Srinivasan MV, Lehrer M, Kirchner WH, Zhang SW (1991) Range perception through apparent image speed in freely flying honeybees. Visual Neurosci 6:519-535.

Srinivasan MV, Zhang SW, Chandrashekara K (1993) Evidence for two distinct movement-detecting mechanisms in insect vision. Naturwissenschaften 80:38-41.

Strausfeld NJ (1970) Golgi studies on insects. Part II. The optic lobes of Diptera. Philos Trans R Soc Lond [Biol] 258:135-223.

Strausfeld NJ (1976) Atlas of an insect brain. Berlin: Springer. 
Strausfeld NJ (1989) Beneath the compound eye: neuroanatomical analysis and physiological correlates in the study of insect vision. In: Facets of vision (Stavenga DG, Hardie RC, eds), pp 317-359. Heidelberg: Springer.

Strausfeld NJ, Bassemir UK (1985) Lobula plate and ocellar interneurons converge onto a cluster of descending neurons leading to neck and leg motor neuropil in Calliphora erythrocephala. Cell Tissue Res 240:617-640.

Strausfeld NJ, Blest AD (1970) Golgi studies on insects. I. The optic lobes of Lepidoptera. Philos Trans R Soc Lond [Biol] 258:81-134.

Strausfeld NJ, Lee J-K (1991) Neuronal basis for parallel visual processing in the fly. Visual Neurosci 7:13-33.

Strausfeld NJ, Nässel DR (1980) Neuroarchitecture of brain regions that subserve the compound eyes of Crustacea and insects. In: Handbook of sensory physiology, Vol VII/6B (Autrum H, ed), pp 1-133. Heidelberg: Springer.
Strausfeld NJ, Kong A, Milde JJ, Gilbert C, Ramaiah L (1995) Oculomotor control in calliphorid flies: GABAergic organization in heterolateral inhibitory pathways. J Comp Neurol 361:298-320.

Van Essen DC, Gallant JL (1994) Neural mechanisms of form and motion processing in the primate visual system. Neuron 13:1-10.

Vaney DI (1990) The mosaic of amacrine cells in the mammalian retina. In: Progress in retinal research, Vol 9 (Osborne NN, Chader G, eds), pp 49-100. Oxford, UK: Pergamon.

Wagner H (1982) Flow-field variables trigger landing in flies. Nature 297:147-148.

Wagner H (1986) Flight performance and visual control of flight of the free-flying housefly (Musca domestica L.) II. Pursuit of targets. Philos Trans R Soc Lond [Biol] 312:553-579.

Wässle H, Boycott BB (1991) Functional architecture of the mammalian retina. Physiol Rev 71:447-480. 